\title{
Problem Based Learning: Learning from the Experiences of Medical Students
}

\author{
${ }^{1}$ Asma Rasheed, ${ }^{2}$ Ahsan Sethi, ${ }^{3}$ Muhammad Afaaq Agha, ${ }^{1}$ Sana Tariq, ${ }^{1}$ Lubna Humayun, \\ ${ }^{4}$ Uzma Shaheen \\ ${ }^{1}$ Department of Pathology, UCMD, University of Lahore \\ ${ }^{2}$ Department of Medical Education, Khyber Medical University, Peshawar \\ ${ }^{3}$ Department of Forensic Medicine, Shaikh Zayed Medical Complex, Lahore \\ ${ }^{4}$ Department of Pathology, Dera Ghazi Khan Medical College, DG Khan
}

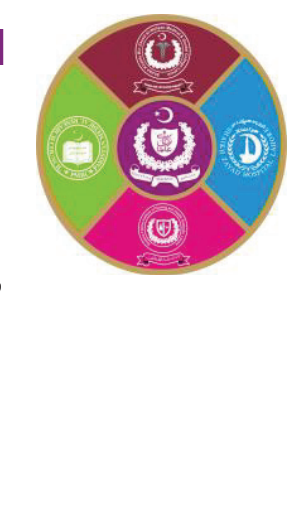

\begin{abstract}
Introduction: Problem based learning (PBL) is student centered learning approach that has been implemented in many medical colleges. Since the literature has controversial takes on the utility of PBL, exploring student perspectives might share insights on the contextual merits and demerits of PBL approach. Aims \& Objectives: To evaluate experience of medical students regarding PBL in hybrid integrated curriculum. Place and duration of study: May to June 2018 at two medical colleges of Lahore (Shalamar Medical College \& University College of Medicine and Dentistry. Material \& Methods: Descriptive cross sectional study conducted in May to June 2018 at two medical colleges. Sample size was 188 students of $1^{\text {st }}$ and $2^{\text {nd }}$ year MBBS of Institute 1 and 110 students of $1^{\text {st }}$ and $2^{\text {nd }}$ year MBBS of Institute 2. Pre validated questionnaire was distributed and students were asked to record their experience about PBL using a 5-point's Likert scale. Data was analyzed by using non-parametric statistics. Results: Institute 1 (188 participants), Institute 2 (110 participants), females being 205 (68.79\%). Mean score $<3$ indicates bad experience while $>3$ indicates good experience about PBL. Results showed that students of both institutes found several key benefits of PBL acquiring critical thinking, problem solving, communication skills and team work. PBL was perceived as better learning approach than lectures. Moreover students of Institute 1 mean score $<3.0$ showed dissatisfaction regarding tutor performance in PBL facilitation which was statistically significant (0.048). Conclusion: It is recommended that tutor and student training should be mandatory before introducing PBL. PBL session marks can be included in internal assessment. Only senior faculty and volunteering to facilitate should conduct PBL sessions.
\end{abstract}

Key words: Problem based learning, Students experiences, PBL tutoring, Skill development, PBL Critical thinking, Teamwork.

\section{INTRODUCTION}

$\mathrm{T}_{1}$ he change of medical education from traditional to integrated curriculum has been adopted by different medical schools worldwide. ${ }^{1}$ Traditional curriculum is teacher centered while integrated curriculum is more inclined towards student centeredness. One of these approaches is problem based learning (PBL). ${ }^{2}$

Problem based learning is implement in medical colleges either as pure or hybrid models. In pure problem based learning model, it is the main teaching and learning strategy adopted throughout the curriculum. Students learning in hybrid problem based learning model is supported by previous knowledge of students through formal lecturing, small group discussion, skill labs before the PBL session. ${ }^{1}$ Few medical schools placed $1^{\text {st }}$ session of PBL at the start of module and students gained knowledge for $2^{\text {nd }}$ session by didactic lectures, small group discussions and by self-directed learning. ${ }^{2}$ Problem based learning is a constructivist pedagogy which has many advantages. It helps students to explore the concepts, build on prior knowledge ${ }^{3}$ so that they become self- directed learners, critical thinkers and problem solvers. Student become able to integrate basic subjects to clinical subjects more better. ${ }^{4}$ In addition, PBL also contributes in the development of communication, interpersonal and presentation skills. ${ }^{5}$

The tutor has important role in PBL sessions as facilitator, to guide students how they keep themselves focused on their objectives. ${ }^{6}$ That's why, 
skilled and trained facilitator plays an important part in the accomplishment of PBL session. ${ }^{7}$

Although most studies tend to report an optimistic and positive impact of PBL on students learning, there are some controversial finding as well. For instance few studies reported that PBL is a time consuming process and it may not have a significant impact on knowledge acquisition. Two studies in this regard had conflicting findings. Chang $\mathrm{J}$ revealed PBL as a positive teaching and learning strategy which enhances student's knowledge and interpersonal skills with potential areas of improvement and continued fine-tuning. ${ }^{8}$ On the other hand, Khan IA suggested that PBL was time taking, resource demanding approach, majority students were unable to identify the benefits of PBL. ${ }^{9}$ These controversial findings demand further exploration of student perceptions.

This study aimed to investigate the experience of medical students in different educational settings to understand the expected PBL outcomes (skill development, studying in PBL small groups, learning preference and tutoring practices). ${ }^{10}$

\section{MATERIAL AND METHODS}

This descriptive cross sectional study was conducted from May 2018 to June 2018 at two different medical colleges, the University College of Medicine and Dentistry, University of Lahore and Shalamar Medical and Dental college Lahore, The targeted population was $1^{\text {st }}$ year and $2^{\text {nd }}$ year MBBS students.

A total of 188 students of $1^{\text {st }}$ year and $2^{\text {nd }}$ year MBBS of the University College of Medicine and Dentistry and 110 students of $1^{\text {st }}$ and $2^{\text {nd }}$ year of Shalamar Medical and Dental College were targeted.

Inclusion criteria: $1^{\text {st }}$ year and $2^{\text {nd }}$ year undergraduate MBBS students of either gender from the academic year 2017-18.

Exclusion criteria: Students of BDS, post graduate students, incomplete questionnaires were excluded, those students not willing to participate.

Data collection technique: This study was based on self-administered and pre-validated questionnaire on experience of medical students regarding PBL. The questionnaire was devised by extensive literature review using the search engines Medline, PubMed and Google scholar. The key words were problem based learning experience of medical students, PBL in integrated curriculum, Prevalidated questionnaire on PBL, Controversial studies on PBL. Questionnaire was reviewed by current research supervisor and piloted on twenty third year medical students.

The questionnaire was divided into four subscales and had total 16 items. The first subscale consisted of 5 questions, which measured the participants experience related to the benefits of Problem based learning sessions regarding skill development. Second subscale consisted of 4 questions, which measured the student's experience of working and study in groups (group dynamics) during and in between PBL session. The third subscale consist of 2 questions which measured students learning preference PBL or lecture. The fourth subscale consisted of 4 questions, which measured the students experience about tutor practice during PBL session. Last item was open ended question, if someone liked to add anything else regarding PBL. These questions were answered on a five point's Likert scale.

Strongly disagree (1), Disagree (2), Neutral (3), Agree (4) and Strongly agree (5)

Ethical approval: The Research Ethical Committee, University College of Medicine and Dentistry, University of Lahore approved the study. Participants were informed about purpose of the study, information about items in the prevalidated questionnaire were explained and study subjects individuality was assured by giving them a code before data analysis.

\section{Statistical analysis:}

Data were coded and entered into Microsoft Excel software and analyzed by using SPSS version 21.0. Data were analyzed and presented as mean \pm SD. Data was not normally distributed, Shapiro Wilk test were applied $(p=0.00)$ therefore non parameter test such as Mann-Whitney -U test were used to identify the significance difference $(p<0.05)$ among the subscale and groups (Institute 1 and 2).

\section{RESULTS}

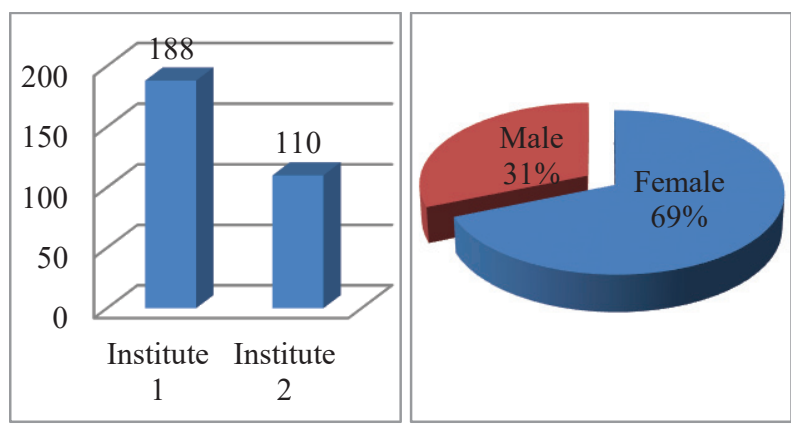

Fig-1: Number of participant Fig-2: Gender distribution of institute wise participants 


\begin{tabular}{|c|c|c|c|c|}
\hline $\begin{array}{l}\text { S. } \\
\text { no }\end{array}$ & Item & $\begin{array}{c}\text { Institue 1 } \\
n=188 \\
\text { Mean } \pm \text { SD }\end{array}$ & $\begin{array}{c}\text { Institue 2 } \\
\mathrm{n}=110 \\
\text { Mean }+ \text { SD }\end{array}$ & $\begin{array}{l}\text { P Value } \\
\text { Institue } \\
1 \text { and } 2\end{array}$ \\
\hline 1 & $\begin{array}{l}\text { I gained critical } \\
\text { thinking skills through } \\
\text { PBL tutorials }\end{array}$ & $3.27 \pm 1.34$ & $3.31 \pm 1.08$ & 0.484 \\
\hline 2 & $\begin{array}{l}\text { I gained problem- } \\
\text { solving skills in PBL } \\
\text { tutorials }\end{array}$ & $3.47 \pm 1.23$ & $3.29+1.02$ & 0.016 \\
\hline 3 & $\begin{array}{l}\text { I gained the ability to } \\
\text { think laterally in } \\
\text { solving problems in } \\
\text { PBL tutorials }\end{array}$ & $3.26 \pm 1.18$ & $3.32 \pm 1.12$ & 0.472 \\
\hline 4 & $\begin{array}{l}\text { I have gained skills in } \\
\text { making diagnosis in } \\
\text { PBL }\end{array}$ & $3.43 \pm 1.23$ & $3.47 \pm 1.05$ & 0.859 \\
\hline 5 & $\begin{array}{l}\text { PBL enhanced my } \\
\text { communication skills } \\
\text { Development }\end{array}$ & $3.67 \pm 1.26$ & $3.56 \pm 1.16$ & 0.12 \\
\hline & Sum (Mean score) & $3.42 \pm 0.16$ & $3.39 \pm 0.11$ & 0.32 \\
\hline 6 & $\begin{array}{l}\text { PBL tutorials promote } \\
\text { team work }\end{array}$ & $3.59 \pm 1.29$ & $3.59 \pm 1.17$ & 0.11 \\
\hline 7 & $\begin{array}{l}\text { Participants in PBL } \\
\text { group contributes } \\
\text { actively in the } \\
\text { discussion } \\
\end{array}$ & $3.17 \pm 1.33$ & $3.07 \pm 1.24$ & 0.987 \\
\hline 8 & $\begin{array}{l}\text { Small groups in PBL } \\
\text { session encourage the } \\
\text { students to share their } \\
\text { ideas in group }\end{array}$ & $3.49 \pm 1.28$ & $3.63 \pm 1.06$ & 0.179 \\
\hline 9 & $\begin{array}{l}\text { Students like to share } \\
\text { their knowledge with } \\
\text { group members in PBL } \\
\text { session }\end{array}$ & $3.69 \pm 1.20$ & $3.55 \pm 1.15$ & 0.08 \\
\hline & Sum (Mean score) & $3.48 \pm 0.22$ & $3.4 \pm 0.22$ & 0.12 \\
\hline 10 & $\begin{array}{l}\text { Students prefer PBL } \\
\text { classes on didactic } \\
\text { lecturing }\end{array}$ & $2.93 \pm 1.32$ & $3.17 \pm 1.18$ & 0.13 \\
\hline 11 & $\begin{array}{l}\text { Students understand } \\
\text { difficult concepts much } \\
\text { better in PBL rather } \\
\text { than teach in a lecture }\end{array}$ & $3.25 \pm 1.34$ & $3.45 \pm 1.18$ & 0.06 \\
\hline & Sum (Mean score) & $3.09 \pm 1.33$ & $3.3 \pm 1.18$ & 0.16 \\
\hline 12 & $\begin{array}{l}\text { Tutor provides a relax } \\
\text { atmosphere during } \\
\text { PBL session }\end{array}$ & $3.19 \pm 1.38$ & $3.46 \pm 1.12$ & 0.007 \\
\hline 13 & $\begin{array}{l}\text { Tutor asks frequent } \\
\text { questions during } \\
\text { session about the } \\
\text { problem being solved }\end{array}$ & $2.65 \pm 1.26$ & $3.22 \pm 1.05$ & 0.197 \\
\hline 14 & $\begin{array}{l}\text { Tutor uses questions to } \\
\text { keep the students on } \\
\text { track }\end{array}$ & $2.45 \pm 1.29$ & $3.41 \pm 1.06$ & 0.009 \\
\hline 15 & $\begin{array}{l}\text { Tutor actively resolves } \\
\text { the conflicts among } \\
\text { group participants }\end{array}$ & $2.80 \pm 1.33$ & $3.50 \pm 1.10$ & 0.02 \\
\hline & Sum (Mean score) & $2.7 \pm 0.32$ & $3.2 \pm 0.4$ & 0.048 \\
\hline
\end{tabular}

Table-1: Evaluation of experience of medical students regarding $\mathrm{PBL}$ in two different institutes.

\section{DISCUSSION}

According to this study, the students of both institutes found PBL a better learning methodology in acquiring critical thinking, problem solving, communication skills and studying in small groups. Pertaining to tutor performance, the institute 1 mean score $<3.0$ showed student's dissatisfaction towards their tutor performance in PBL conduction, $\mathrm{P}$ value (0.048) is statistically significant.

In imparting skill development subscale (item 1-5) the mean score of Institute 1 was 3.42 , which is higher than Institute 2(3.39), that was good response (Table-1). This shows that the PBL system of the Institute 1 is more effective in imparting skill development competencies in its students as compared to the Institute 2.

Regarding group process subscale (item 6-9) the mean score was 3.4 for both institute which is a concurrent finding. The PBL system is equally effective in both institutes when it comes to the outcome of group process.

Pertaining to learning preference subscale (item 1011) the mean score of Institute 1 and Institute 2 is 3.09 and 3.4 respectively. Both institutes showed adequate response but the institute 2 is lead in generating learning preferences about PBL system. Regarding tutor practice subscale (item 12-15) the mean score of Institute 1 was 2.7 which showed their dissatisfaction towards tutor practice in PBL conduction while the mean score of Institute 2 was 3.2 which was superior response towards their tutor practice in PBL conduction.

The finding was similar to those from Turan etal, in which students are not satisfied with their tutor performance in PBL process. This may be because of unpreparedness of tutor for PBL (tutor didn't go through facilitator guide for PBL), lack of training of faculty who were involved in PBL conduction. On the other hand students of Institute 1 devalued their tutors because of other factors, as students may have had issues with a specific tutor or vice versa. It is suggested that proper and frequent training sessions should be conducted for faculty, hiring of more qualified, experienced faculty and, assigning PBL to well versed, passionate faculty members and voluntary participants so they follow all steps of PBL in true spirit. This finding is supported by another study conducted by El Aziz El Naggar ${ }^{11}$ in which he evaluated the educational effectiveness of implementing a facilitator training workshop. Results of his study showed that facilitator training workshop was effective in improving tutor facilitation skills in the areas of constructive active learning, collaborative learning, self-directed 
learning, and increased the educational outcomes of the PBL sessions from students.

It was observed in open ended question of this study survey, most of the students complained that PBL marks were not included in internal evaluation, therefore students were not taking PBL and tutor sincerely. It was deduced that PBL marks should be included in internal evaluation. ${ }^{12}$

Results of this study showed that students found PBL a better learning approach with successful outcome. That PBL should be commenced by more medical colleges gradually, to extract and spread advantages of PBL. The study also revealed the importance of evaluation of effectiveness and weaknesses of existing PBL model which would eventually help in improvement through feedback of actual product of this system.

This cross-sectional study was based on selfreported information provided by the students and on convenient sampling method. Due to limited time frame, this was a pilot study of small sample size in between two institutes only.

Similar studies should be conducted in other medical colleges, upon introduction of PBL as one of the methods of active learning in curriculum. Their faculty and administrative staff involvement is essential for data regarding logistics, feedback, concerns and hindrances pertaining to PBL.

\section{CONCLUSION}

This study reveals that medical students of both institutes consider PBL as valuable learning methodology. It also emphasizes the important role of PBL in curriculum which enables self reflection in students, regarding enhancement in their different learning skills and helps students assess their tutor performance during PBL conduction. The investigator strongly recommends tutor and student training be made mandatory before introducing PBL.

\section{REFERENCES}

1. Al-Drees AA, Khalil MS, Irshad M, Abdulghani HM. Students' perception towards the problem based learning tutorial session in a system-based hybrid curriculum. Saudi Med J.2015;36(3):341-8

2. Hande S, Mohammed CA, Komattil R. Acquisition of knowledge, generic skills and attitudes through problem-based learning: Student perspectives in a hybrid curriculum. J Taibah Univ Med Sci. 2015; 10(1):21-5.

3. Jawawi R, Matzin R, Shahrill M, Jaidin JH. The Benefits of Adopting a Problem-Based Learning Approach on Students. Learning Developments in Secondary Geography Lessons. 2016; 1(2): 25-27.

4. Silva A, Bispo A, Rodriguez D, Vasquez F. Problem-based learning, Revista de Gestão. 2018; 25(2):160-177.

5. Pagander L, Read J. Is Problem-Based Learning (PBL) An Effective Teaching Method ? A study Based on Existing Reserch. Seminariedatum. 2014; 581(83):1-45.

6. Yew EHJ, Goh K. Problem-Based Learning: An Overview of its Process and Impact on Learning. Heal Prof Educ. 2016; 2(2):75-9.

7. Wijnen M, Loyens SMM, Smeets G, Kroeze M, van der Molen $\mathrm{H}$. Comparing problem-based learning students to students in a lecture-based curriculum: learning strategies and the relation with self-study time. Eur J Psychol Educ. 2017; 32(3):431-47.

8. Chang JB. Problem-based learning in medical school: A student's perspective. Annals of Medicine and Surgery. 2016; 12:88-89

9. Khan AI, Al-Swailmi FK. Perceptions of faculty and students regarding Problem Based Learning: A mixed methods study. J Pak Med Assoc. 2015; 65(12):1334-38.

10. Azu OO. A survey of problem-based learning and traditional methods of teaching anatomy to 200 level pharmacy students of the University of Lagos , Nigeria. Humanity \& Social Sciences Journal. 2014; 5(2):105-111.

11. El Aziz, El Naggar. Effectiveness of Implementing a Tutor Training Workshop for Problem Based Learning Class Tutors at the Faculty of Medicine, Suez Canal University. Intel Prop Rights. 2013; 1(1):1-10.

12. Cavanagh A, Vanstone M, Ritz S. Problems of problem-based learning:Towards transformative critical pedagogy in medical education. Perspect Med Educ. 2019; 8(1):38-42.

13. Mahmood SU, Syed F, Khan NR, Batool Z, Rehman R.Comparison of problem based with case based learning. Pak J Physiol. 2017; 13(4):52-6.

\section{The Authors:}

Dr. Asma Rasheed

Assistant Professor,

Department of Pathology,

UCMD, The University of Lahore.

Dr. Ahsan Sethi

Assistant Professor,

Department of Medical Education,

Institute of Health Professions Education and Research, Khyber Medical University, Peshawar 
Dr. Muhammad Afaaq Agha Assistant Professor

Department of Forensic Medicine, Shaikh Zayed Medical Complex, Lahore.

Dr. Sana Tariq

Demonstrator,

Department of Pathology,

UCMD, The University of Lahore.

Dr. Lubna Humayun

Assistant Professor,

Department of Pathology,

UCMD, The University of Lahore.
Dr. Uzma Shaheen

Assistant Professor,

Department of Pathology,

Dera Ghazi Khan Medical College, DG Khan.

\section{Corresponding Author:}

Dr. Asma Rasheed

Assistant Professor,

Department of Pathology,

UCMD, The University of Lahore.

E-mail: asma.rasheed@ucm.uol.edu.pk 